\section{Commentary: Cor triatriatum dexter: A tale of 2 horns}

\author{
Sameh M. Said, MBBCh, MD, FACS
}

An important component of the primitive heart tube is the sinus venosus with its 2 horns. The left horn obliterates leaving 2 remnants: the oblique vein of left atrium (of Marshall) and the coronary sinus, whereas the right horn is what constitutes the major part of the right atrium (RA) (smooth part) and is separated by the sinoatrial orifice from the primitive atrium. Two venous valves guard this sinoatrial orifice, the right and left venous valves. The right valve regresses between the ninth and 15th week, leaving the Eustachian and Thebesian valves of the inferior vena cava (IVC) and the coronary sinus, respectively. ${ }^{1}$ It is the persistence of the right venous valve that results in partitioning the RA into 2 separate chambers and creates what is known as cor triatriatum dexter $(\mathrm{CTD})^{2}$ to differentiate it from its counterpart on the left side.

This is among the rarest cardiac malformation, and very limited number of cases have been reported on so far. Kalangos and colleagues ${ }^{3}$ reviewed the literature for CTD and identified only 13 cases in addition to their report. However, the majority of CTD cases may not require surgical intervention, so the true incidence may not be known with certainty but is estimated to be $<0.01 \%$.

The term CTD should be used only to describe anomalous septation of the RA in which the membrane is welldeveloped enough to interfere with a normal venous return within the RA. Other misleading abnormalities include dilated coronary sinus with prominent Thebesian valve, prominent Eustachian valve, ${ }^{5}$ and persistent Chiari network ${ }^{6}$; however, an important defining feature is the presence of atrial septal attachment for a true CTD.

\footnotetext{
From the Division of Pediatric Cardiovascular Surgery, Masonic Children's Hospital, University of Minnesota, Minneapolis, Minn.

Disclosures: Dr Said is a consultant for Cryolife.

The Journal policy requires editors and reviewers to disclose conflicts of interest and to decline handling or reviewing manuscripts for which they may have a conflict of interest. The editors and reviewers of this article have no conflicts of interest.

Received for publication Sept 1, 2020; revisions received Sept 1, 2020; accepted for publication Sept 5, 2020; available ahead of print Sept 14, 2020.

Address for reprints: Sameh M. Said, MBBCh, MD, FACS, Division of Pediatric Cardiovascular Surgery, Masonic Children's Hospital, University of Minnesota, 2450 Riverside Ave S, East Building, MB 539, Minneapolis, MN 55454 (E-mail: ssaid@ umn.edu).

JTCVS Techniques 2020;4:259-60

2666-2507

Copyright (C) 2020 The Authors. Published by Elsevier Inc. on behalf of The American Association for Thoracic Surgery. This is an open access article under the CC BY-NCND license (http://creativecommons.org/licenses/by-nc-nd/4.0/).

https://doi.org/10.1016/j.xjtc.2020.09.005
}

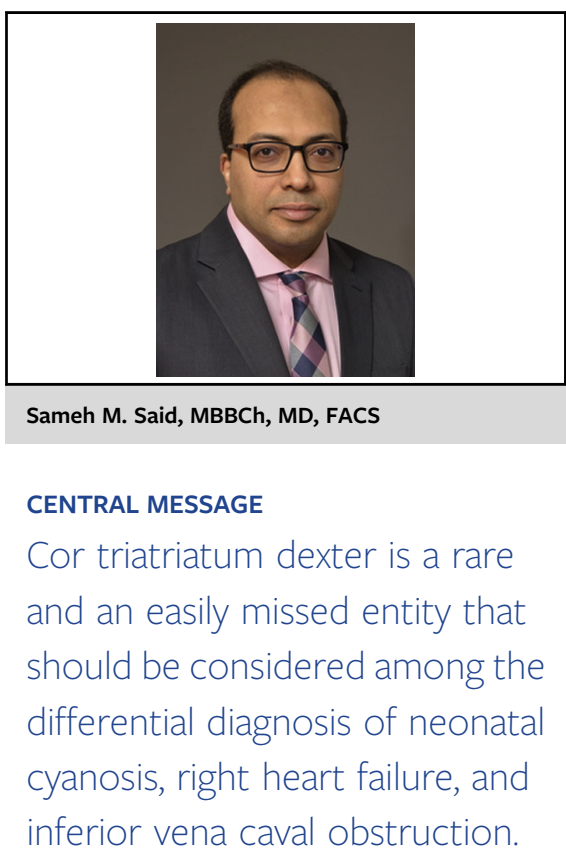

CTD can be associated with right-sided heart malformation such as Ebstein anomaly, tricuspid or pulmonary valve stenosis, or atresia and hypoplastic right ventricle, and it can be an important but rare cause of neonatal cyanosis in the presence of a concomitant atrial level shunt.

The occurrence of clinical manifestations and the need for intervention in these cases depend on several factors: the obstructive versus nonobstructive nature of the membrane, presence of atrial communication, associated tricuspid valve abnormalities, and size and compliance of the right-sided heart structures. Most severe cases present with right heart failure, tricuspid valve obstruction with elevated central venous pressure, or a picture of suprahepatic portal hypertension (Budd-Chiari syndrome) due to IVC obstruction. ${ }^{8}$

It is also important to consider that this membrane, if present, has the potential to obstruct interventional cardiac catheterization procedures. ${ }^{4}$ Asymptomatic patients are generally not treated and if intervention is warranted, several techniques have been described, including transcatheter disruption of the membrane ${ }^{9}$ and surgical resection via a transatrial approach.

CTD is a rare and an easily missed entity that should be considered among other potential etiologies for right-to-left shunt with cyanosis in neonates, right heart failure, and IVC obstruction, and is important to rule out before any right-sided interventional catheterization procedures. 


\section{References}

1. Shirani J, Kalyanasundaram A, Pourmoghadam KK. Cor tri-atriatum. Available at: http://www.emedicine.com/med/topic458.htm. Accessed September 20,2020

2. Hansing CE, Young WP, Rowe GG. Cor triatriatum dexter. Persistent right sinus venosus valve. Am J Cardiol. 1972;30:559-64.

3. Kalangos A, Shatelen N, Demyanchuk V, Ruban N, Sfyridis P, Todurov B. Cor triatriatum dexter in children: literature review and case report. J Thorac Cardiovasc Surg Tech. 2020;4:254-8.

4. Vukovic PM, Kosevic D, Milicic M, Jovovic L, Stojanovic I, Micovic S. Cor triatriatum dexter and atrial septal defect in a 43-year-old woman. Tex Heart Inst J. 2014;41:418-20.
5. Martinez-Quintana E, Rodriguez-Gonzalez F, Marrero-Santiago H, SantanaMontesdeoca J, Lopez-Gude MJ. Cor triatriatum dexter versus prominent Eustachian valve in an adult congenital heart disease patient. Congenit Heart Dis. 2013;8:589-91.

6. Islam AKMM, Sayami LA, Zaman S. Chiari network: a case report and brief overview. J Saudi Heart Assoc. 2013;25:225-9.

7. Hoye DJ, Wilson EC, Fyfe DA, Guzzetta NA. Cor triatriatum dexter: a rare cause of neonatal cyanosis. Anesth Analg. 2010;110:716-8.

8. Rajekar H, Vasishta RK, Chawla YK, Dhiman RK. Noncirrhotic portal hypertension. J Clin Exp Hepatol. 2011;1:94-108.

9. Savas V, Samyn J, Schreiber TL, Hauser A, O'Neill WW. Cor triatriatum dexter: recognition and percutaneous transluminal correction. Cathet Cardiovasc Diagn. 1991;23:183-6. 